\title{
Spatiotemporal Contribution of Blue-green Spaces to the Urban Thermal Environment in Changsha, China
}

\author{
Xinyi Qiu, ${ }^{1}$ Sung-Ho Kil, ${ }^{*}$ and Chan Park ${ }^{2}$ \\ ${ }^{1}$ Department of Ecological Landscape Architecture Design, Kangwon National University, \\ Gangwon-Dae-Hak-Gil 1, Chuncheon, Ganwondo 24341, South Korea \\ ${ }^{2}$ Department of Landscape Architecture, University of Seoul, Seoulsilipdaero 163, Seoul 02504, South Korea
}

(Received February 22, 2021; accepted April 20, 2021)

Keywords: blue-green space evolution, thermal environment evolution, cooling effect, remote sensing

Urban thermal environment issues have become a potential threat to the urban ecosystem and residents' health. Thermal environment issues in Changsha are becoming more serious with the expansion of built-up areas and the decrease in the area of blue-green spaces. In this study, the spatiotemporal evolution of blue-green spaces and their influence on the thermal environment of Changsha from 1988 to 2019 were assessed using Landsat images. The results show that the loss of blue-green spaces and the exacerbation of thermal environment issues in Changsha began around 1999. Over the study period, the total area of blue-green spaces decreased by $427.27 \mathrm{~km}^{2}$, corresponding to $16.5 \%$ of the study area, leading to an increase in the average land surface temperature (LST) of Changsha of $2.59{ }^{\circ} \mathrm{C}$. During summer, the cooling effect of water is the highest among all blue-green space types, which is $-1.29{ }^{\circ} \mathrm{C}$, followed by cropland $\left(-0.82{ }^{\circ} \mathrm{C}\right)$ and forest $\left(-0.55{ }^{\circ} \mathrm{C}\right)$. However, the cooling effect of forest in other seasons is always greater than that of cropland. The cooling effect of blue-green spaces in spring, summer, and fall is generally greater than that in winter. Over the study period, the temperature increases caused by spatial changes from water, cropland, and forest to built-up areas are $1.39,1.17$, and $1.1{ }^{\circ} \mathrm{C}$, respectively.

\section{Introduction}

In recent decades, urban thermal environment issues have become increasingly serious with global urbanization because of the rapid expansion of built-up areas and the loss of urban bluegreen spaces. ${ }^{(1,2)}$ Issues caused by the degradation of the urban thermal environment, such as the deterioration of the urban ecological environment and the increased health risk for urban residents, have attracted extensive attention. ${ }^{(3,4)}$ The urban heat island effect, as a typical phenomenon of the urban thermal environment, concentrates polluted air in the center of the city, threatening the health of residents by increasing the incidence of respiratory and skin diseases. ${ }^{(5-9)}$ Moreover, the high temperatures caused by the effect can significantly increase the incidence of cardiovascular and cerebrovascular diseases and the death rate. ${ }^{(10-12)}$ For example, in the hot summer of 2003 in Europe, about 70000 heat-related extra deaths occurred. ${ }^{(13)}$

${ }^{*}$ Corresponding author: e-mail: sunghokil@kangwon.ac.kr https://doi.org/10.18494/SAM.2021.3341 
China has been undergoing rapid urbanization over the past 30 years, and urban regions cover an area up to 12 times larger than that in 1981.(14) According to the National Bureau of Statistics of China (2015), the urbanization rate of China is expected to reach $60 \%$ by $2030 .{ }^{(15)}$ How to improve the urban thermal environment has become an issue of key importance for future urban planning.

With the advantages of being both environmentally friendly and economically cost-effective, increasing the area of blue-green spaces is the most effective way to improve the urban thermal environment. ${ }^{(16-19)}$ Blue-green spaces are defined as land covered by vegetation or water, e.g., forests, grass, cropland, rivers, and lakes. ${ }^{(20)}$ Owing to the different thermodynamic properties of blue-green spaces and built-up areas, the temperature of blue-green spaces is lower than that of built-up areas; thus, increasing the area of blue-green spaces can significantly reduce the average temperature of urban regions. ${ }^{(21,22)}$ The cooling effect of blue-green spaces on the land surface temperature (LST) is also determined by its spatial pattern, e.g., the cooling effect is more apparent when the shape of blue-green spaces is more complex. ${ }^{(23-26)}$ Moreover, owing to their different thermodynamic properties, the cooling effects of different types of blue-green spaces vary greatly. However, there have been few reports on the transformation of blue-green spaces during the different stages of the urbanization process and its impact on the urban thermal environment.

In Changsha, one of the ten hottest cities in China, both the area of blue-green spaces in the city and their spatial pattern have changed drastically with the acceleration of the urbanization process. As a result, the thermal environment of Changsha has become a serious issue in the last 30 years. However, research on the thermal environment of Changsha has primarily focused on the changes in the spatial characteristics of the thermal environment. ${ }^{(27-29)}$ There have been few studies focusing on the influence of the evolution of blue-green spaces on the thermal environment, and none that quantify the cooling effect of a city's blue-green spaces.

The objective of this study is to comparatively analyze the spatiotemporal evolution of bluegreen spaces and the thermal environment in Changsha using remote sensing images from 1988 to 2019, and quantitatively analyze the cooling effect of blue-green spaces on the urban thermal environment. First, LST and blue-green space datasets from 1988 to 2019 were obtained from thermal IR and optical images of Landsat, respectively. Second, the spatial and temporal dynamic changes of blue-green spaces and LST were assessed using the datasets. Finally, the cooling effect of different types of blue-green spaces on the urban thermal environment as well as the impact of the transformation of blue-green spaces on the urban thermal environment were evaluated quantitatively. The results of this study provide scientific support for improving the urban thermal environment and building ecological and livable cities in the future.

\section{Research Methods}

\subsection{Study area}

Changsha is one of the ten hottest cities in China (Fig. 1), where extremely high air temperatures $\left(>35^{\circ} \mathrm{C}\right)$ are common and long-lasting during the summer. ${ }^{(30)}$ According to the 


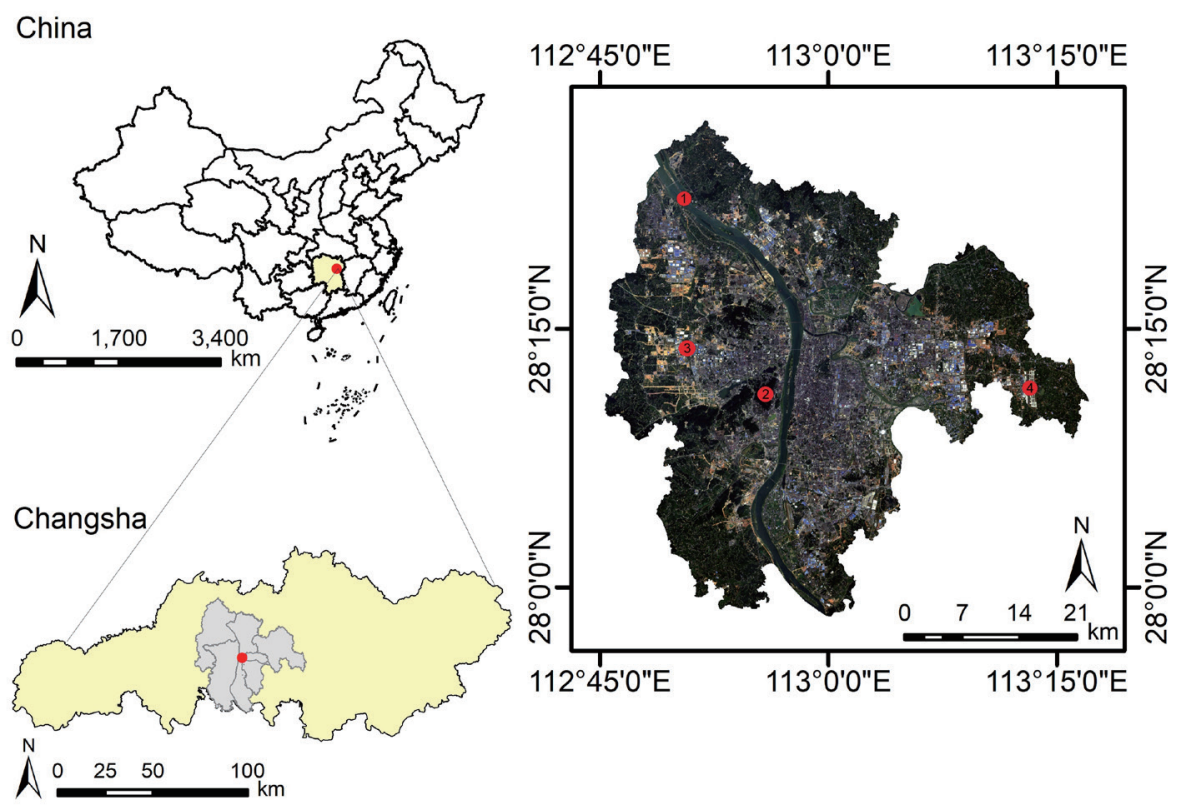

Fig. 1. (Color online) Location of study area. In the right figure, 1 and 2 indicate Xiangjiang River and Mount Yuelu, respectively, which are two typical stable blue-green spaces in Changsha; 3 and 4 indicate Lugu Industrial Park and Huanghua International Airport, respectively, which are typical areas where blue-green spaces have been converted to non-blue-green spaces.

2019 Hunan Statistical Yearbook published by Hunan Provincial Bureau of Statistics, the city's population increased from approximately 4.5 million in the 1980 s to 8.2 million in 2018, and Changsha has an urbanization rate of $77.59 \% .^{(31)}$

Rainfall in Changsha is abundant owing to its subtropical monsoon climate, with an annual rainfall of approximately $1500 \mathrm{~mm}$. The precipitation is greatest from April to June, rather than during the warmest months (July and August). The city's annual average air temperature is approximately $17.2^{\circ} \mathrm{C}$. However, the average air temperature in July and August is as high as $30{ }^{\circ} \mathrm{C} .{ }^{(32)}$ Considering that the highest air temperatures and the least rainfall occur in the warmest months, the thermal environment of Changsha is most severe during this period. Additionally, the near-surface airflow in the urban zone is blocked by the surrounding terrain (hills and hummocks), which, coupled with the dense urban buildings and automobile exhaust emissions, exacerbates thermal environment issues in Changsha.

\subsection{LST retrieval}

The LST, as a key factor affecting the near-surface air temperature and a useful index that can be obtained easily through remote sensing data, has been widely used in studies of urban thermal environments. ${ }^{(33)}$ In this study, the LST was retrieved from Landsat thermal IR images and the mono-window algorithm. ${ }^{(34)}$

The evolution of the thermal environment of Changsha from 1988 to 2019 is discussed from two aspects: (1) the evolution during the warmest season (summer) and (2) the evolution among 
the four seasons. All available thermal Landsat IR images from 1988 to 2019 were used to obtain the LST in summer to explore the spatiotemporal changes in the thermal environment of Changsha as well as the cooling effect of blue-green spaces on the urban thermal environment. On the other hand, thermal Landsat IR images taken in the four seasons were used to obtain the LST in each season to reveal seasonal differences in the cooling effect of blue-green spaces on the urban thermal environment. However, owing to the limited availability of Landsat images, very few thermal IR images cover four consecutive seasons. All the thermal IR images used in this study are listed in Table 1. The original spatial resolution of the thermal IR bands was $120 \mathrm{~m}$ for band 6 of TM5 and $100 \mathrm{~m}$ for band 1 of TIRS; however, thermal IR data released online have been resampled to $30 \mathrm{~m}$ by the data producer to match the spatial resolution of visible bands.

The input parameters for the mono-window algorithm, which was adopted to retrieve LST in this study, are land surface emissivity, atmospheric transmissivity, brightness temperature, and average atmospheric temperature. The standard formula of the mono-window algorithm used to obtain LST $\left(T_{s}\right)$ can be expressed as

$$
\begin{gathered}
T_{s}=\left\{a(1-C-D)+[b(1-C-D)+C+D] T-D T_{a}\right\} / C, \\
C=\varepsilon \tau, \\
D=(1-\varepsilon)[1+(1-\varepsilon) \tau],
\end{gathered}
$$

where $T$ is the brightness temperature of the thermal IR band (i.e., band 6 of TM5 and band 1 of TIRS), $\varepsilon$ is the emissivity of the land surface, and $\tau$ is the atmospheric transmissivity in the thermal IR band. ${ }^{(35)}$ Given the spectral difference between band 6 of TM5 $(10.4-12.5 \mu \mathrm{m})$ and band 1 of TIRS (10.6-11.2 $\mu \mathrm{m})$, the values of parameters $a$ and $b$ are also different, where $a=$ -67.355351 and $b=0.458606$ for band 6 of TM5, while $a=-64.6081$ and $b=0.4399$ for band 1 of TIRS. $T_{a}$ is the average atmospheric temperature, which can be calculated by Eqs. (4) and (5), where $T_{0}$ is the atmospheric temperature provided by China Meteorological Data Service Center. Specifically, Eq. (4) is suitable for calculating $T_{a}$ in spring, summer, and fall, whereas Eq. (5) is adopted to calculate $T_{a}$ in winter.

\begin{tabular}{|c|c|c|c|c|}
\hline \multicolumn{2}{|c|}{ Summer } & \multicolumn{3}{|c|}{ Four seasons } \\
\hline Date & Sensor & \multirow{5}{*}{$\begin{array}{c}\text { Group 1: } \\
\text { 2008-2009 }\end{array}$} & Date & Sensor \\
\hline 1988.07.10 & TM5 & & 2008.12 .08 & TM 5 \\
\hline 1991.07 .19 & TM5 & & 2009.04 .15 & TM5 \\
\hline 1993.08 .25 & TM5 & & 2009.08 .21 & TM5 \\
\hline 1998.08.23 & TM5 & & 2009.10 .24 & TM5 \\
\hline 1999.07 .25 & TM5 & & & \\
\hline 2009.08.21 & TM5 & \multirow{5}{*}{$\begin{array}{l}\text { Group 2: } \\
\text { 2013-2014 }\end{array}$} & Date & Sensor \\
\hline 2011.07.26 & TM5 & & 2013.05 .28 & TIRS \\
\hline 2013.07 .31 & TIRS & & 2013.07 .31 & TIRS \\
\hline 2018.07 .29 & TIRS & & 2013.09 .17 & TIRS \\
\hline 2019.08.17 & TIRS & & 2014.01 .23 & TIRS \\
\hline
\end{tabular}

Table 1

Landsat thermal IR images taken in the summer and in four consecutive seasons used in the study. 


$$
\begin{aligned}
& T_{a}=16.0110+0.92621 T_{0}+273.15 \\
& T_{a}=19.2701+0.91118 T_{0}+273.15
\end{aligned}
$$

To describe the evolution of the thermal environment in summer, the results of LST over the past 30 years were divided into six levels: ultrahigh temperatures (level $1,41.1-45.6{ }^{\circ} \mathrm{C}$ ), high temperatures (level 2, 36.6-41.1 ${ }^{\circ} \mathrm{C}$ ), sub-high temperatures (level 3, 32.1-36.6 ${ }^{\circ} \mathrm{C}$ ), medium temperatures (level 4, 27.6-32.1 ${ }^{\circ} \mathrm{C}$ ), sub-low temperatures (level 5, 23.1-27.6 ${ }^{\circ} \mathrm{C}$ ), and low temperatures (level 6, 18.5-23.1 ${ }^{\circ} \mathrm{C}$ ). Each level contains an equal temperature range, and 45.6 and $18.5{ }^{\circ} \mathrm{C}$ were the maximum and minimum LST values during the whole study period, respectively.

\subsection{Blue-green space and non-blue-green space data}

In this study, three types of blue-green space (forest, cropland, and water) and two types of non-blue-green space (bare land and built-up areas) are considered. Notably, cropland in Changsha is mainly composed of rice paddy fields, which contain a large amount of water throughout the growing season, making it significantly different from typical cropland for growing wheat or corn in northern China. The blue-green space and non-blue-green space data were obtained from Landsat optical images by a supervision classification method. To test the classification accuracy, 300 random points were selected and then interpreted using highresolution spatial images from Google Earth. The validation results showed that the overall accuracy of the classification results was above $90 \%$.

\subsection{Relative land surface temperature (RLST) index}

Considering the weather variability and time difference in remote sensing images, the RLST was adopted as an index to investigate the effect of different land-cover types on the thermal environment of the study area over the study period. ${ }^{(36)}$ The RLST is given by

$$
R L S T_{i}=L S T_{i}-L S T_{\text {mean }}
$$

where $R L S T_{i}$ is the RLST of land-cover type $i, L S T_{i}$ is the LST of land-cover type $i$, and $L S T_{\text {mean }}$ is the average LST of the study area. A negative RLST indicates a cooling effect of the specified land-cover type in the study area, whereas a positive RLST indicates a heating effect.

\subsection{Cooling coefficient transformation index}

The cooling coefficient transformation index $k$ is defined by the difference between RLST at two different times and given by Eq. (7). It was introduced to describe the effect of different blue-green space transformations on the thermal environment, including blue-green space extension (any type of space is converted to blue-green space), and blue-green space loss (bluegreen space is converted to non-blue-green space). 


$$
k=R L S T_{2}-R L S T_{1}
$$

Here, $R L S T_{1}$ is the RLST for the original land-cover type in the previous year and $R L S T_{2}$ is the RLST for the different land-cover type after its transformation in a later year. Similar to the RLST, a negative value of $k$ indicates a cooling effect of the transformation, whereas a positive value indicates a heating effect. A larger magnitude of $k$ indicates a greater impact.

\section{Results}

\subsection{Evolution of blue-green space from 1988 to 2019}

The total area of blue-green spaces decreased by $34.60 \%$ from $1242.12 \mathrm{~km}^{2}$ in 1988 to $814 \mathrm{~km}^{2}$ in 2019. Moreover, the areas of all types of blue-green space decreased significantly from 1988 to 2019 (Table 2), with the area of cropland showing the greatest reduction of $343.66 \mathrm{~km}^{2}$ from 1988 to 2019 , a decrease of $65.1 \%$, followed by water $\left(36.16 \mathrm{~km}^{2}, 25.0 \%\right)$ and forest $\left(47.45 \mathrm{~km}^{2}, 8.3 \%\right)$. In contrast, the built-up area increased 5.5-fold from 1988 to 2019.

The proportion of each type of blue-green space changed markedly from 1988 to 2019. Cropland accounted for $42.48 \%$ of the city's blue-green space in 1988, whereas it accounted for only $22.59 \%$ of the blue-green space in 2019 . This reduction is directly due to urban expansion; the area of cropland that was converted to built-up areas between 1988 and 2019 was $223.89 \mathrm{~km}^{2}$ (Table 3). In contrast, forest accounted for $45.87 \%$ of the total blue-green space in the city in 1998 but for $64.10 \%$ of the space in 2019 . This phenomenon was due to the reduction in the total blue-green space area over the study period rather than afforestation; a decrease in the forested area was observed between 1988 and 2019. The change in the area of water was irregular due to the seasonal and annual changes in the amount of precipitation and flood events. For example,

Table 2

Area $\left(\mathrm{km}^{2}\right)$ of different types of blue-green space and their proportions of the study area in four different years.

\begin{tabular}{lcccccccccc}
\hline \multirow{2}{*}{ Year } & \multicolumn{2}{c}{ Bare land } & \multicolumn{2}{c}{ Built-up areas } & \multicolumn{2}{c}{ Cropland } & \multicolumn{2}{c}{ Forest } & \multicolumn{2}{c}{ Water } \\
\cline { 2 - 13 } & Area & $\%$ & Area & $\%$ & Area & $\%$ & Area & $\%$ & Area & $\%$ \\
\hline 1988 & 88.33 & 6.14 & 107.12 & 7.45 & 527.70 & 36.71 & 569.77 & 39.63 & 144.65 & 10.06 \\
\hline 1998 & 35.16 & 2.45 & 182.57 & 12.70 & 451.96 & 31.44 & 568.83 & 39.57 & 199.06 & 13.85 \\
\hline 2009 & 66.88 & 4.65 & 367.20 & 25.54 & 384.23 & 26.73 & 516.87 & 35.95 & 102.4 & 7.13 \\
\hline 2019 & 34.99 & 2.43 & 587.99 & 40.89 & 184.04 & 12.80 & 522.32 & 36.33 & 108.49 & 7.91 \\
\hline
\end{tabular}

Table 3

Transformation matrix $\left(\mathrm{km}^{2}\right)$ between blue-green and non-blue-green space types between 1988 and 2019.

\begin{tabular}{lcccccc}
\hline \multirow{2}{*}{2019} & \multicolumn{7}{c}{1988} \\
\cline { 2 - 7 } & Bare land & Built-up areas & Cropland & Forest & Water & Total \\
\hline Bare land & - & 1.35 & 14.77 & 14.71 & 1.73 & 32.56 \\
\hline Built-up areas & 48.97 & - & 223.89 & 192.84 & 37.87 & 503.57 \\
\hline Cropland & 3.75 & 1.96 & - & 41.09 & 9.2 & 56.00 \\
\hline Forest & 31.04 & 12.90 & 144.05 & - & 18.98 & 206.97 \\
\hline Water & 2.14 & 6.52 & 17.03 & 5.92 & - & 31.61 \\
\hline Total & 85.9 & 22.73 & 399.74 & 254.56 & 67.78 & - \\
\hline
\end{tabular}


the largest area of water was observed in $1998\left(199.06 \mathrm{~km}^{2}\right)$, which was due to the extreme flood of the Yangtze River Basin in 1998.

Cropland was the type of land that was transformed at the fastest rate between 1988 and 2019, with a total area of $399.74 \mathrm{~km}^{2}$ lost to other land-cover types; $223.89 \mathrm{~km}^{2}$ was converted to builtup areas, whereas $144.05 \mathrm{~km}^{2}$ became forest. A total area of $254.56 \mathrm{~km}^{2}$ of forest was converted to other types of land, with $192.84 \mathrm{~km}^{2}$ converted to built-up areas and $41.09 \mathrm{~km}^{2}$ converted to cropland. Over the study period, half of the bare land was converted to built-up areas and approximately $36 \%$ was converted to forest, whereas half of the water area was converted to built-up areas.

The spatial pattern of blue-green spaces also changed dramatically from 1988 to 2019 (Fig. 2). In 1988, the blue-green spaces in Changsha occupied large areas ( $84 \%$ of the total area) and had high spatial connectivity. By 2019, the area of blue-green spaces had decreased to $34.4 \%$ while the number of blue-green spaces was $26.7 \%$ higher than that in 1988 , showing the severe fragmentation of blue-green spaces. This was due to large and spatially continuous blue-green
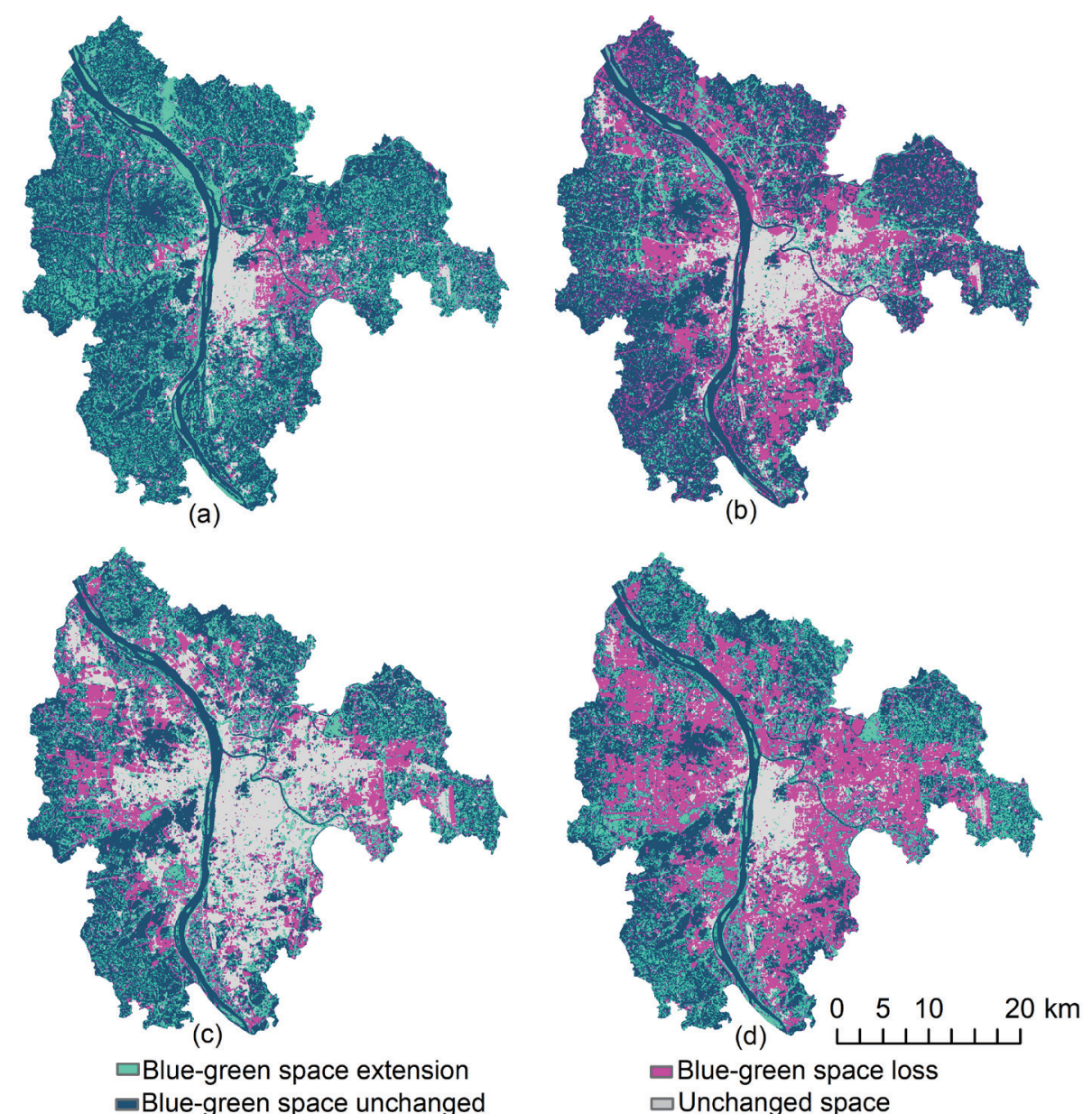

Fig. 2. (Color online) Evolution of blue-green spaces over time: (a) 1988-1998, (b) 1998-2009, (c) 2009-2019, and (d) 1988-2019. 
spaces being divided into small areas with the development of built-up areas. Secondly, artificial blue-green spaces are generally small and highly dispersed owing to the high cost of land in urban areas and a lack of spatially continuous green belts. Thirdly, spatially connected bluegreen spaces occupied most of the study area in 1988, while the urbanized area of the city was limited to the east of Xiangjiang River and around Mount Yuelu. However, as urbanization occurred from 1998 to 2009, large-scale urban development and rapid construction of highways from 1998 to 2009 resulted in a sharp decrease in the area of blue-green spaces. From 2009 to 2019, the urban region continued to expand. With the completion of Huanghua Airport in the east, a high-speed railway station in the south, and Lugu Industrial Park in the northwest, the surrounding areas developed rapidly, thereby accelerating the fragmentation of blue-green spaces and leading to an overall decrease in the blue-green spaces footprint.

\subsection{Evolution of thermal environment from 1988 to 2019}

The spatial distribution trend of LST in Changsha in summer can be clearly divided into three stages: 1988-1998, 1998-2009, and 2009-2019 (Fig. 3). During 1988-1998, LST was noticeably much smaller than in 1998-2009 and 2009-2019. From 1988 to 1998, there were almost no regions characterized by ultrahigh or high temperatures $\left(>36.6^{\circ} \mathrm{C}\right)$ and there was a relatively uniform spatial distribution of LST. From 1998 to 2009, the area with high temperatures increased by $0.81 \mathrm{~km}^{2}$, while no area exhibited ultrahigh temperatures. Then, from 2009 to 2019, the area with ultrahigh and high temperatures substantially increased to a total of $22.15 \mathrm{~km}^{2}$, where the areas with ultrahigh temperatures in 2013 and 2019 was 0.13 and $1.05 \mathrm{~km}^{2}$, respectively. The increasing LST was due to the rapid urbanization of Changsha, which started in the 21st century, as part of the implementation of the "Rising of the Central Regions" policy. The spatial changes in the high-LST regions are consistent with the urban expansion and the spatial distribution of built-up areas. The urban high-temperature areas (levels 1 and 2) are primarily concentrated in the densely populated industrial and commercial areas. This indicates that the process of urbanization has aggravated urban thermal environment problems and validates the concept that the loss of blue-green spaces leads to an increase in LST.

Regarding the temporal evolution of LST, the differences between the lowest LST, highest LST, and average LST in 1988 and 1998 were 2.2, 0.1, and $1.9^{\circ} \mathrm{C}$, respectively. The average LST did not change substantially during this period; therefore, the exacerbation of thermal environment issues was not evident. From 1998 to 2009, the difference between the lowest LST was $2.2^{\circ} \mathrm{C}$, whereas the highest LST increased by $2.7^{\circ} \mathrm{C}$, and the average LST increased by $2.6^{\circ} \mathrm{C}$. The rise in LST continued up to 2019; compared with 2009; the highest, lowest, and average LSTs in 2019 were 5.5, 5, and $1.9{ }^{\circ} \mathrm{C}$ higher, respectively. The results showed an increasing trend in the LST over the past 30 years, contributing to a more severe thermal environment.

The LSTs of the four consecutive seasons in 2008-2009 and 2013-2014 were selected to describe the seasonal differences in the thermal environment characteristics (Fig. 4). From 2008 to 2009 , the mean LSTs in spring, summer, fall, and winter were $26.6,29.0,21.3$, and $12.1{ }^{\circ} \mathrm{C}$, respectively. In these seasons, the areas where LST was $>30^{\circ} \mathrm{C}$ were $98.98,326.8,0.25$, and 


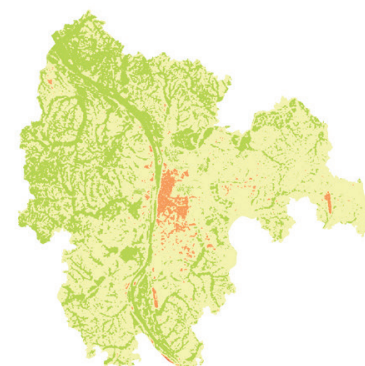

(a)1988

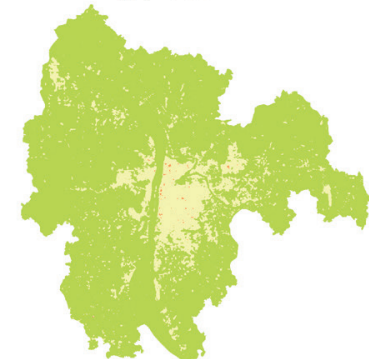

(d)1998

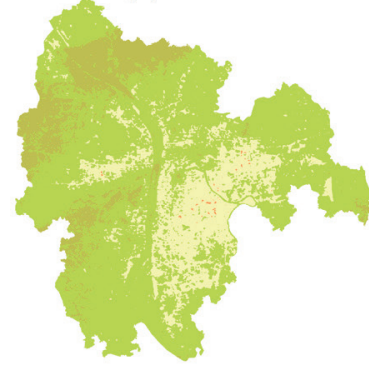

(g)2011

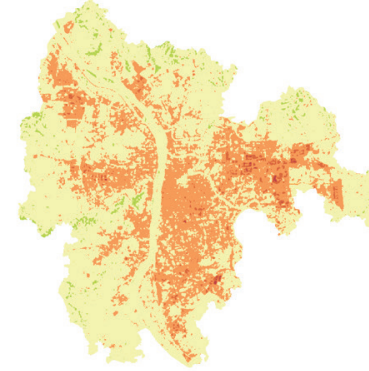

(j)2019

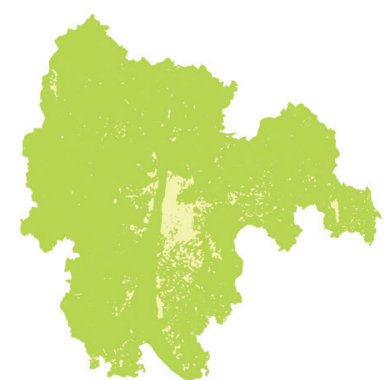

(b)1991

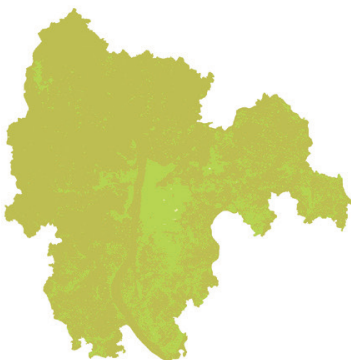

(e)1999

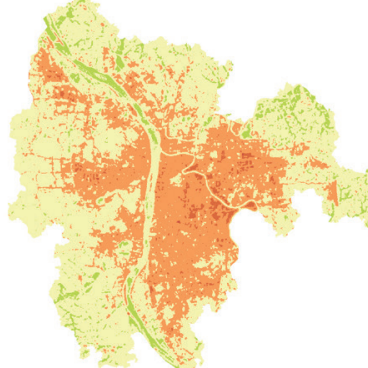

(h)2013

level $1,41.1-45.6^{\circ} \mathrm{C}$ level $2,36.6-41.1^{\circ} \mathrm{C}$ level $3,32.1-36.6^{\circ} \mathrm{C}$ level $4,27.6-32.1^{\circ} \mathrm{C}$ level $5,23.1-27.6^{\circ} \mathrm{C}$ level $6,18.5-23.1^{\circ} \mathrm{C}$

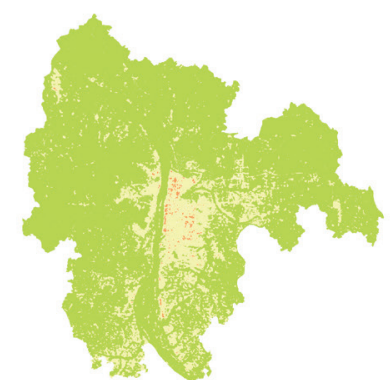

(c)1993

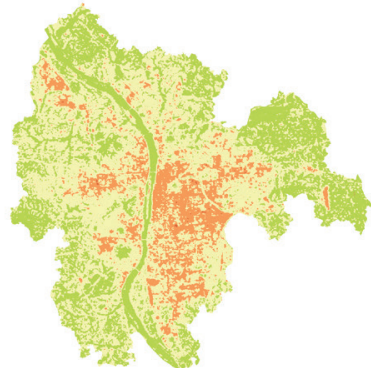

(f)2009

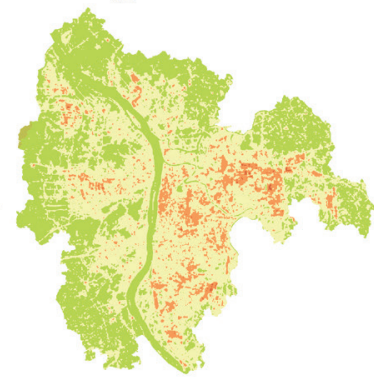

(i)2018

Fig. 3. (Color online) LST of the study area in summer: (a) 1988, (b) 1991, (c) 1993, (d) 1998, (e) 1999, (f) 2009, (g) 2011, (h) 2013, (i) 2018, and (j) 2019.

$0 \mathrm{~km}^{2}$, respectively. For 2013 to 2014, the mean LSTs in spring, summer, fall, and winter were 26.8, 31.2, 32.8, and $11.4{ }^{\circ} \mathrm{C}$, and the areas with LST $>30{ }^{\circ} \mathrm{C}$ were $121.43,429.09,300.57$, and $0 \mathrm{~km}^{2}$, respectively. The results showed that thermal environment issues may occur in any season except for winter. Owing to the combined effect of the subtropical monsoon climate and Changsha's relatively low latitude, the high temperatures in the city are long-lasting and can persist from late spring to early fall. 


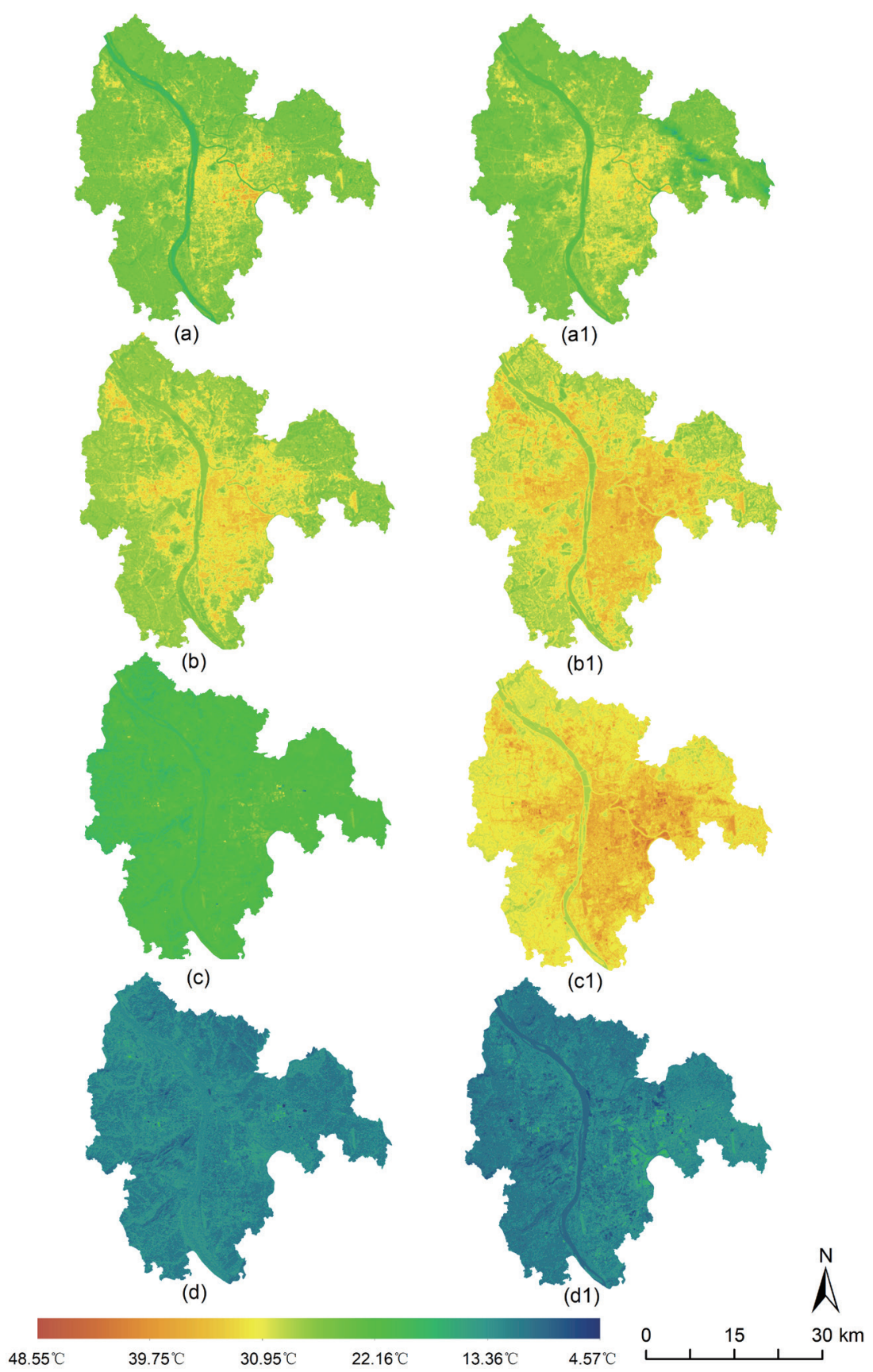

Fig. 4. (Color online) LST of the study area in (a, a1) spring, (b, b1) summer, (c, c1) fall, and (d, d1) winter for 2008-2009 and 2013-2014, respectively.

\subsection{Influence of evolution of blue-green spaces on the thermal environment}

For summer, the influence of the evolution of blue-green spaces on the thermal environment of Changsha is obvious. For example, the average LST of Changsha increased by $2.59^{\circ} \mathrm{C}$ during the period when the total area of blue-green spaces decreased by 16.5\% (Table 4). From 1988 to 
Table 4

Changes in average LST and the total area of blue-green spaces between different years.

\begin{tabular}{ccccccc}
\hline Year & LST $\left({ }^{\circ} \mathrm{C}\right)$ & Area $(\%)$ & & Year & LST $\left({ }^{\circ} \mathrm{C}\right)$ & Area $(\%)$ \\
\hline $1988-1991$ & -2.19 & 2.94 & & $1998-2013$ & 4.76 & -25.37 \\
\hline $1988-1993$ & -1.40 & 0.30 & & $1998-2018$ & 2.26 & -21.68 \\
\hline $1988-2009$ & 0.75 & -16.60 & & $1998-2019$ & 4.48 & -28.18 \\
\hline $1988-2013$ & 2.87 & -26.92 & & $1999-2009$ & 6.36 & -15.50 \\
\hline $1988-2018$ & 0.37 & -23.23 & & $1999-2011$ & 2.83 & -14.61 \\
\hline $1988-2019$ & 2.59 & -29.73 & & $1999-2013$ & 8.48 & -25.82 \\
\hline $1991-1993$ & 0.79 & -2.63 & & $1999-2018$ & 5.98 & -22.14 \\
\hline $1991-1998$ & 0.30 & -4.49 & $1999-2019$ & 8.20 & -28.63 \\
\hline $1991-2009$ & 2.94 & -19.54 & $2009-2011$ & -3.53 & 0.90 \\
\hline $1991-2013$ & 5.06 & -29.85 & $2009-2013$ & 2.12 & -10.32 \\
\hline $1991-2018$ & 2.56 & -26.17 & $2009-2019$ & 1.84 & -13.13 \\
\hline $1991-2019$ & 4.78 & -32.67 & $2011-2013$ & 5.65 & -11.21 \\
\hline $1993-2009$ & 2.15 & -16.90 & $2011-2018$ & 3.15 & -7.53 \\
\hline $1993-2013$ & 4.27 & -27.22 & $2011-2019$ & 5.37 & -14.03 \\
\hline $1993-2018$ & 1.77 & -23.54 & $2013-2018$ & -2.50 & 3.68 \\
\hline $1993-2019$ & 3.99 & -30.04 & $2018-2019$ & 2.22 & -6.50 \\
\hline $1998-1999$ & -3.72 & 0.45 & & & \\
\hline $1998-2009$ & 2.64 & -15.05 & Mean & 2.59 & -16.5 \\
\hline
\end{tabular}

1991, the area of blue-green spaces in Changsha as a proportion of the total area increased by $2.9 \%$ and the average LST decreased by $2.19^{\circ} \mathrm{C}$; from 1991 to 1998 , the proportion decreased by $4.5 \%$ and the average LST increased by $0.3{ }^{\circ} \mathrm{C}$; from 1998 to 2009 , the proportion decreased by $15.1 \%$ and the average LST increased by $2.64{ }^{\circ} \mathrm{C}$; and from 2009 to 2019 , the proportion decreased by $13.1 \%$ and the average LST increased by $1.84{ }^{\circ} \mathrm{C}$. Overall, from 1988 to 2019 , the proportion decreased by $29.73 \%$ and the average LST increased by $2.59{ }^{\circ} \mathrm{C}$.

A negative RLST indicates a cooling effect of the specified land-cover type on the thermal environment, whereas a positive RLST indicates a heating effect. Thus, spatiotemporal changes in RLST give a more detailed description of the influence of blue-green spaces on the urban thermal environment.

First, during summer, the area with a positive RLST increased owing to the expansion of non-blue-green spaces (Fig. 5), which was consistent with the spatial trend of blue-green space loss. The spatial change in RLST can also be divided into three time periods, 1988-1998, 19982009, and 2009-2019, which is consistent with the spatial changes in LST in Changsha. From 1988 to 1998 , the area with a positive RLST decreased from 485.3 to $415.7 \mathrm{~km}^{2}$, with the area with RLST $>1{ }^{\circ} \mathrm{C}$ decreasing from $241.88 \mathrm{~km}^{2}$ in 1988 to $214.1 \mathrm{~km}^{2}$ in 1998 . The overall change in the area with a positive RLST was relatively small, i.e., thermal environment issues were concentrated in a small region and were not prominent during this period. From 1998 to 2009, the area with a positive RLST increased by $128.5 \mathrm{~km}^{2}$, accounting for $8.9 \%$ of the total area, and the area with RLST $>1{ }^{\circ} \mathrm{C}$ increased by $204.14 \mathrm{~km}^{2}$, accounting for $14.2 \%$ of the total area. From 2009 to 2019, the area with a positive RLST further increased to $610 \mathrm{~km}^{2}$, accounting for $42.4 \%$ of the total area, and the area with RLST $>1{ }^{\circ} \mathrm{C}$ increased to $462.02 \mathrm{~km}^{2}$, accounting for $32 \%$ of the total area. 


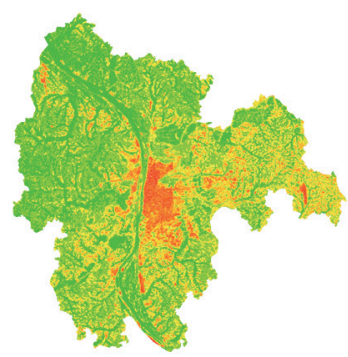

(a) 1988

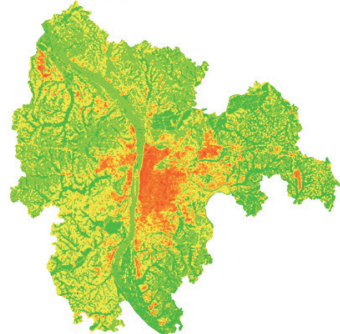

(d) 1998

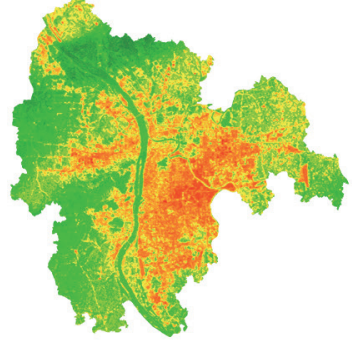

(g)2011

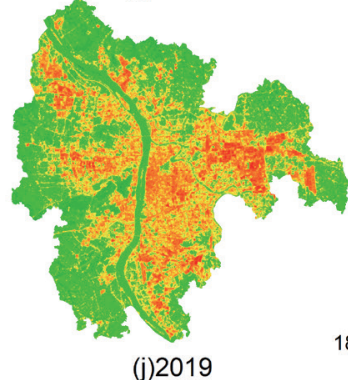

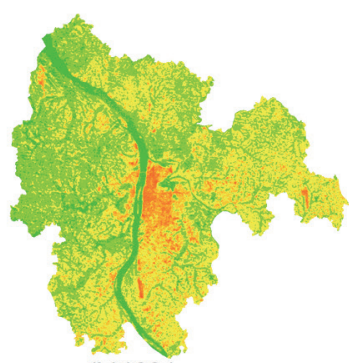

(b) 1991

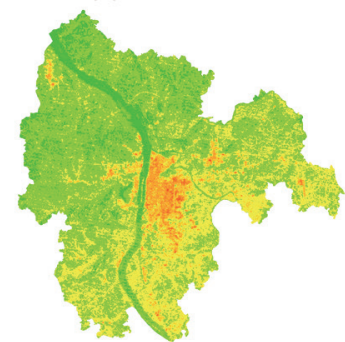

(e)1999

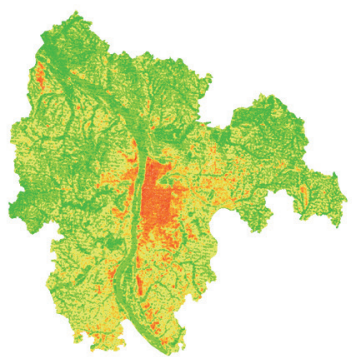

(c) 1993

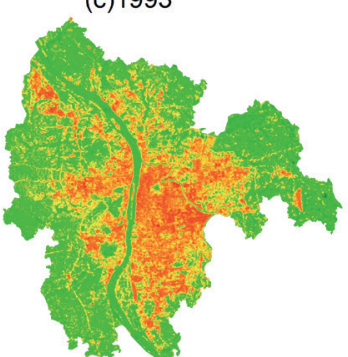

(f) 2009

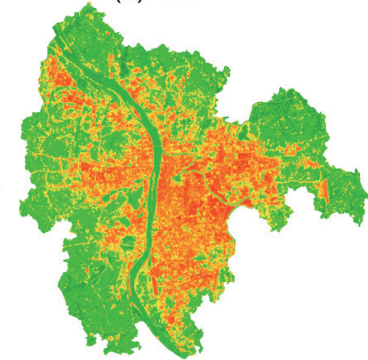

(h)2013

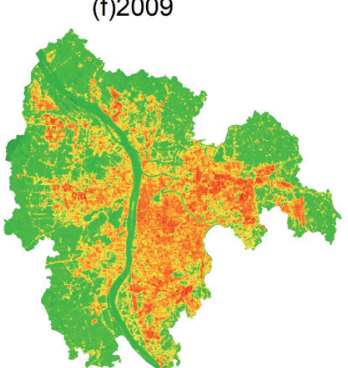

(i) 2018

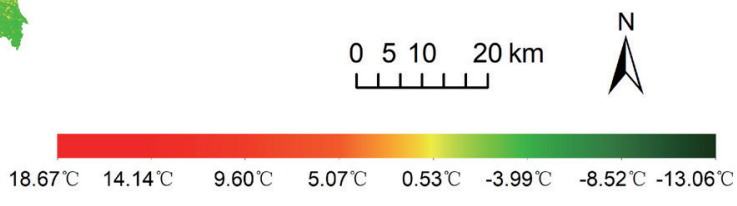

Fig. 5. (Color online) RLST of the study area in summer: (a) 1988, (b) 1991, (c) 1993, (d) 1998, (e) 1999, (f) 2009, (g) 2011, (h) 2013, (i) 2018, and (j) 2019.

Second, the RLST showed different spatial characteristics among the four seasons (Fig. 6). In 2008 to 2009, the areas with a positive RLST in spring, summer, fall, and winter were 533.91, $544.21,645.7$, and $609.71 \mathrm{~km}^{2}$, and the areas with RLST $>2{ }^{\circ} \mathrm{C}$ were $214.5,302.5,73.25$, and $46.1 \mathrm{~km}^{2}$, respectively. From 2013 to 2014, the areas with a positive RLST in spring, summer, fall, and winter were $536.05,606.87,574.82$, and $589.09 \mathrm{~km}^{2}$, and the areas with RLST $>2{ }^{\circ} \mathrm{C}$ were $254.31,373.59,286.41$, and $95.65 \mathrm{~km}^{2}$, respectively. The area with RLST $>2{ }^{\circ} \mathrm{C}$ in winter was substantially lower than that in spring, summer, and fall during 2008-2009 and 2013-2014. In other words, thermal environment issues mainly occur during the spring, summer, and fall in Changsha. 


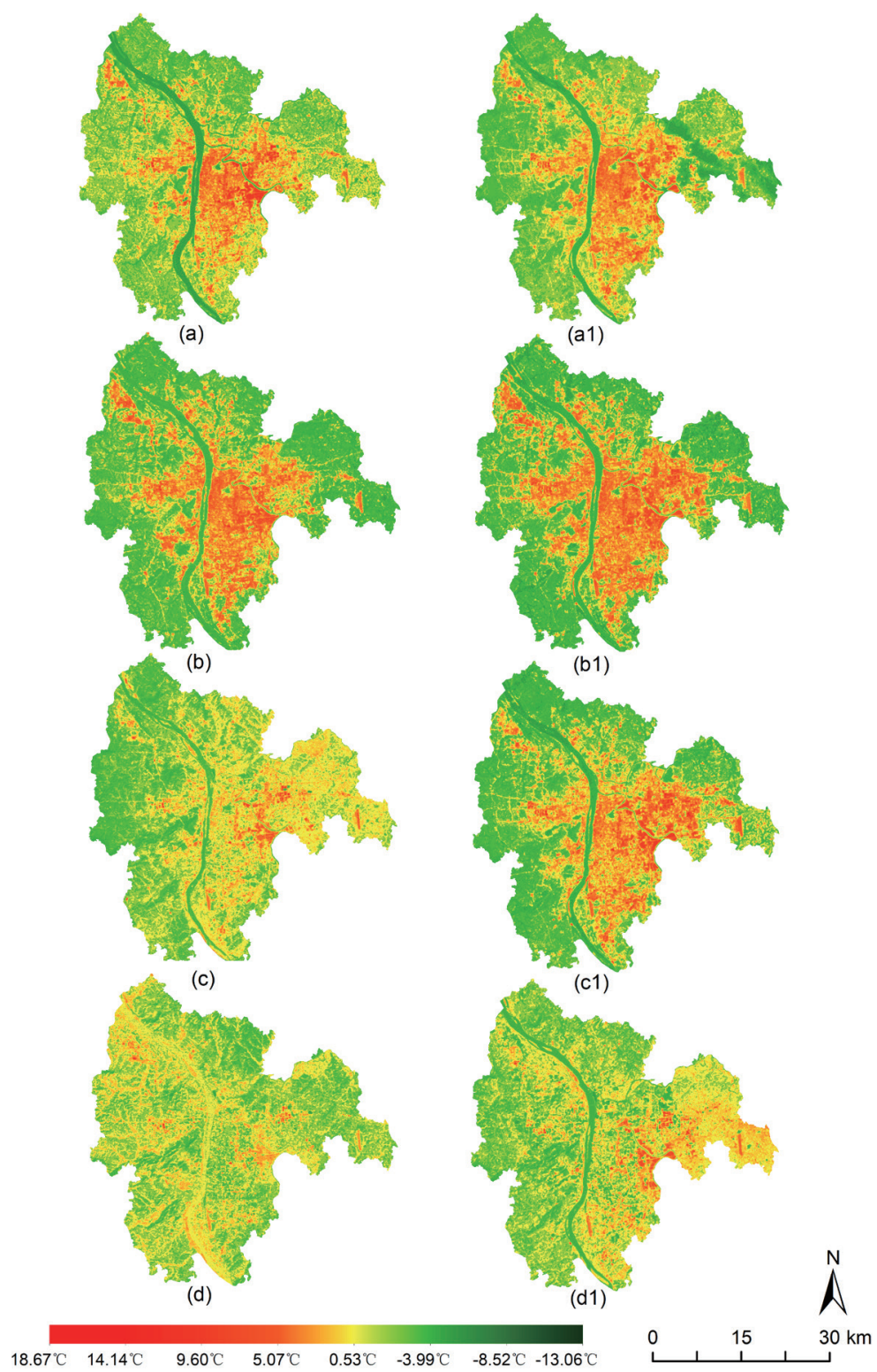

Fig. 6. (Color online) RLST of the study area in (a, al) spring, (b, b1) summer, (c, cl) fall, and (d, d1) winter in 2008-2009 and 2013-2014, respectively.

\subsection{Cooling effect of different types of blue-green spaces}

The mean RLST of each type of blue-green space was used to evaluate its cooling effect on the urban thermal environment, considering that the RLST of each type of blue-green space is different. During summer, water has the greatest average cooling effect $\left(-1.29^{\circ} \mathrm{C}\right)$, followed by cropland $\left(-0.82{ }^{\circ} \mathrm{C}\right)$ and forest $\left(-0.55^{\circ} \mathrm{C}\right)$. For the non-blue-green spaces, built-up areas $\left(2.17^{\circ} \mathrm{C}\right)$ exhibit a stronger heating effect on the thermal environment than bare land $\left(1.52{ }^{\circ} \mathrm{C}\right)($ Table 5$)$. 
Table 5

RLST of all blue-green and non-blue-green space types during summer from 1988 to 2019 (unit: ${ }^{\circ} \mathrm{C}$ ).

\begin{tabular}{lccccc}
\hline Date & Bare land & Built-up areas & Cropland & Forest & Water \\
\hline 1988.07 .10 & 1.62 & 2.69 & -0.6 & -0.07 & -0.68 \\
\hline 1991.07 .19 & 0.41 & 1.76 & -0.28 & 0.13 & -0.79 \\
\hline 1993.08 .25 & 1.48 & 2.2 & -0.55 & -0.06 & -0.60 \\
\hline 1998.08 .23 & 1.76 & 2.36 & -0.86 & -0.05 & -0.47 \\
\hline 1999.07 .25 & 0.53 & 1.10 & 0.46 & -0.30 & -0.66 \\
\hline 2009.08 .21 & 2.34 & 2.55 & -0.94 & -0.91 & -1.42 \\
\hline 2011.07 .26 & 2.01 & 2.17 & -0.63 & -0.98 & -1.73 \\
\hline 2013.07 .31 & 2.41 & 2.71 & -1.57 & -0.87 & -2.30 \\
\hline 2018.07 .29 & 1.45 & 2.07 & -1.20 & -0.97 & -2.75 \\
\hline 2019.08 .17 & 1.15 & 2.1 & -2.06 & -1.41 & -1.47 \\
\hline Mean & 1.52 & 2.17 & -0.82 & -0.55 & -1.29 \\
\hline
\end{tabular}

Table 6

RLST of blue-green and non-blue-green space types in the four seasons (unit: ${ }^{\circ} \mathrm{C}$ ).

\begin{tabular}{|c|c|c|c|c|c|c|}
\hline Seasons & & Bare land & Built-up areas & Cropland & Forest & Water \\
\hline \multirow{3}{*}{ Spring } & 2009.04 .15 & 0.56 & 2.34 & -0.59 & -0.44 & -4.30 \\
\hline & 2013.05 .28 & 2.83 & 2.00 & -0.21 & -1.11 & -2.32 \\
\hline & Mean & 1.70 & 2.17 & -0.40 & -0.78 & -3.31 \\
\hline \multirow{3}{*}{ Summer } & 2009.08 .21 & 2.34 & 2.55 & -0.94 & -0.91 & -1.42 \\
\hline & 2013.07 .31 & 2.41 & 2.71 & -1.57 & -0.87 & -2.30 \\
\hline & Mean & 2.38 & 2.63 & -1.26 & -0.89 & -1.86 \\
\hline \multirow{3}{*}{ Fall } & 2009.10 .24 & 0.55 & 1.08 & 0.52 & -0.70 & -0.85 \\
\hline & 2013.09 .17 & 1.39 & 2.31 & -0.58 & -1.22 & -2.50 \\
\hline & Mean & 0.97 & 1.70 & -0.03 & -0.96 & -1.66 \\
\hline \multirow{3}{*}{ Winter } & 2008.12 .08 & 0.41 & 0.34 & 0.24 & -0.50 & -0.12 \\
\hline & 2014.01 .23 & 0.16 & 0.48 & 0.15 & -0.27 & -1.35 \\
\hline & Mean & 0.29 & 0.41 & 0.20 & -0.39 & -0.74 \\
\hline
\end{tabular}

For all four seasons, water has the greatest cooling effect among the types of blue-green spaces (Table 6). This is due to its high specific heat capacity and strong evapotranspiration at the water surface, making the temperature of water increase slowly and remain much lower than the temperature of the surrounding area. ${ }^{(37-39)}$ The cooling effect of water is strongest in the spring $\left(-3.31{ }^{\circ} \mathrm{C}\right)$, followed by summer $\left(-1.86^{\circ} \mathrm{C}\right)$, fall $\left(-1.66^{\circ} \mathrm{C}\right)$, and winter $\left(-0.74{ }^{\circ} \mathrm{C}\right)$.

The cooling effect of forest in the four seasons is greater than that of cropland except for summer. The cooling effect of forest mainly resulted from the strong evapotranspiration and shading effect of forest, which is generally greater than that of cropland; consequently, the forest temperature is normally lower than that of cropland. However, during summer, the evaporation of a large amount of water from rice paddy fields results in the absorption of a lot of heat, giving cropland a lower temperature than forest. ${ }^{(40-42)}$ Moreover, the large canopy of rice appearing in summer also enhances the cooling effect of cropland. The greater cooling effect of cropland in summer than in the other seasons is also closely related to the seasonal changes in the air temperature and the vegetation canopy at different stages of the growth period. For example, the cooling effect of cropland decreases significantly after rice has been harvested. 
The RLSTs of all types of non-blue-green space are positive, namely, they clearly have a heating effect on the urban thermal environment. The heating effect of built-up areas is stronger than that of bare land. Because the specific heat capacity of built-up areas is generally lower than that of bare land (bare soil in this study), the temperature of built-up areas is generally higher than that of bare land when subjected to the same amount of solar radiation.

\subsection{Cooling coefficient transformation}

Over the past three decades, the transformation among blue-green and non-blue-green space types has been obvious in Changsha. The range and average value of $k$ for different transformations from blue-green to non-blue-green space types are shown in Fig. 7. For example, considering the difference in conversion area (size) during different change patterns, the average value $\left(1.38^{\circ} \mathrm{C}\right)$ from cropland to bare land means that the average heating effect was $1.38{ }^{\circ} \mathrm{C}$ for this changing region over the study period. For the case of blue-green space changing to built-up areas, the heating effect was $1.39,1.17$, and $1.1{ }^{\circ} \mathrm{C}$, respectively, when water, cropland, and forest changed to built-up areas. For the case of blue-green space changing to bare land, the heating effect was $1.25,1.38$, and $1.26^{\circ} \mathrm{C}$, respectively, when water, cropland, and forest changed to bare land. In conclusion, all forms of blue-green space loss resulted in an increase in LST of $>1{ }^{\circ} \mathrm{C}$, while the loss of water had the greatest impact on the urban thermal environment $\left(0.61-2.51^{\circ} \mathrm{C}\right)$.

The range and average value of $k$ for the extension of different types of blue-green spaces are shown in Fig. 8. The results show that the case of non-blue-green space changing to water has the greatest cooling effect, followed by the transformation of non-blue-green space to cropland or forest. For example, the cooling effect increased by $0.96,0.65$, and $0.8{ }^{\circ} \mathrm{C}$, respectively, when bare land was converted to water, forest, and cropland. For the case that built-up areas changed to blue-green space, the cooling effect increased by $0.91{ }^{\circ} \mathrm{C}$ (water), $0.44{ }^{\circ} \mathrm{C}$ (forest), and $0.38{ }^{\circ} \mathrm{C}$ (cropland). The cooling range of the transformation between different blue-green spaces shows

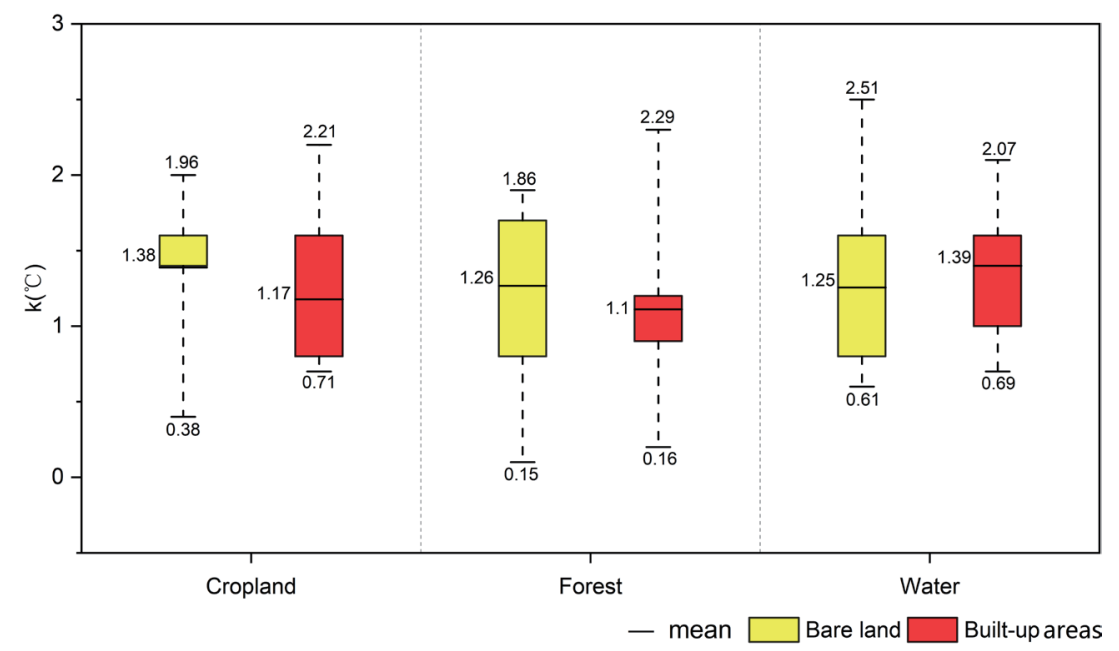

Fig. 7. (Color online) Cooling coefficient transformation index $(k)$ during blue-green space loss in summer. 


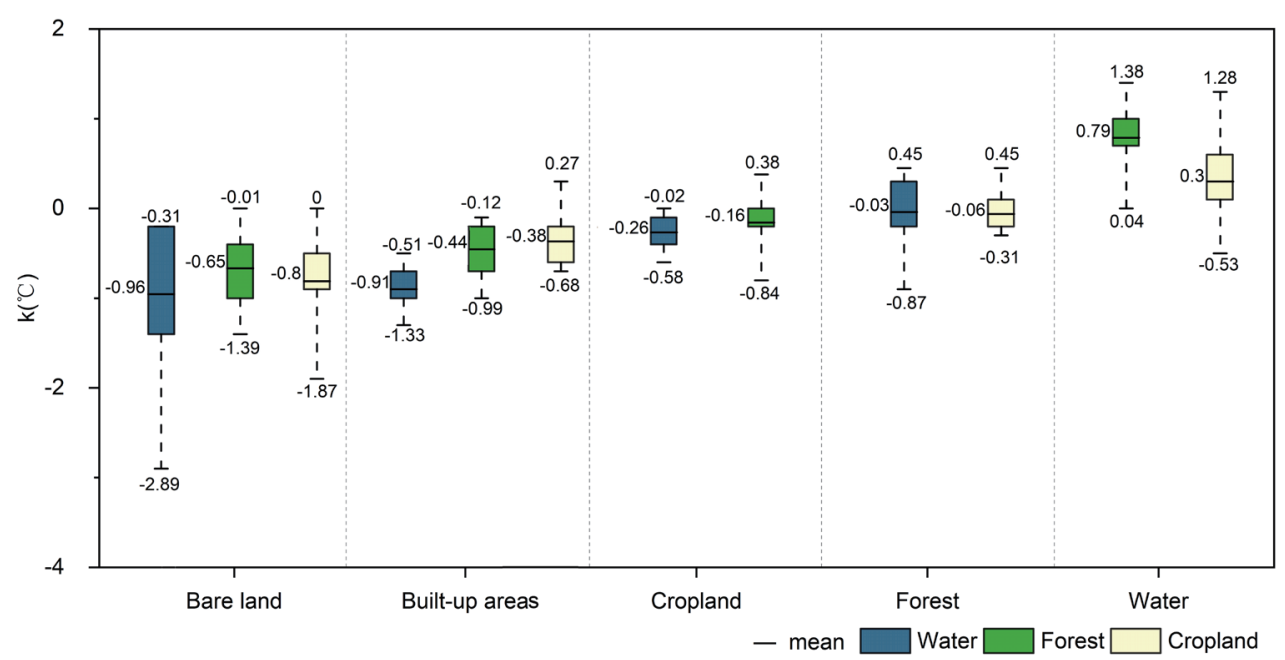

Fig. 8. (Color online) Cooling coefficient transformation index ( $k$ ) during blue-green space extension in summer.

both positive and negative values with a relatively small interval. This implies that the cooling effect of transforming between blue-green spaces is closely related to the location of the transformation and the surrounding area. When cropland is converted to water or forest, the mean values of $k$ are -0.26 and $-0.16{ }^{\circ} \mathrm{C}$, respectively. When forest is converted to water or cropland, the mean values are -0.03 and $-0.06{ }^{\circ} \mathrm{C}$, respectively. When water is converted to forest or cropland, the mean values are 0.79 and $0.3^{\circ} \mathrm{C}$, respectively.

\section{Discussion}

Owing to the limited availability of Landsat images, some years of the LST derived from Landsat images are not optimal. For example, the LST of 1988 is higher than those of 1991, 1993, and 1998, and the LST of 2001 is lower than that of 1999. This phenomenon is directly related to the weather on specific days, since LST is greatly affected by the weather. Namely, differences in the weather may result in an obvious difference in LSTs even though Landsat images were chosen from the same season and even the same date on different years. However, the overall spatiotemporal trends of the LST of Changsha over the entire study period are still clear.

The cooling effect of water on the urban thermal environment may have been underestimated. Considering the medium resolution of thermal IR images of Landsat, the mixed-pixel phenomenon is common for urban areas, and the surface temperature of water (especially regions with small areas) will be overestimated. As a result, the RLST of water obtained in this study may be smaller than its actual value.

The cropland in the study area mainly comprises rice paddy fields, which exhibit a better cooling effect than forest in summer since the large amount of water in the fields significantly enhances the cooling effect. This finding is consistent with the results reported by Thiery et al. ${ }^{(40)}$ However, cropland for growing wheat or corn, which is considerably different from rice paddy fields, was not discussed in this study owing to the lack of detailed land-cover data. 


\section{Conclusions}

Spatiotemporal changes in the thermal environment and blue-green spaces of Changsha, as well as the cooling effect of blue-green spaces, were examined in this study on the basis of Landsat data. The findings of this study will provide some useful guidelines for the future urban planning of Changsha as well as other cities facing similar issues.

The total area of blue-green spaces within the city decreased by $427.27 \mathrm{~km}^{2}$ from 1988 to 2019 , with cropland having the greatest loss of area $\left(343.66 \mathrm{~km}^{2}, 65.1 \%\right)$, followed by water $\left(36.16 \mathrm{~km}^{2}, 25.0 \%\right)$ and forest $\left(47.45 \mathrm{~km}^{2}, 8.3 \%\right)$. In contrast, the built-up area increased by $480.87 \mathrm{~km}^{2}$, nearly 5.5 -fold, from 1988 to 2019 . The spatiotemporal changes in the blue-green spaces and thermal environment of Changsha could be divided into three stages, i.e., 1988-1998 (slow change), 1998-2009 (rapid change), and 2009-2019 (extremely rapid change).

Over the entire study period (1988 to 2019), the loss of blue-green spaces was $16.5 \%$, leading to an increase of $2.59{ }^{\circ} \mathrm{C}$ in the average LST. During summer, the area with a positive RLST increased with the expansion of non-blue-green spaces. The area with RLST $>1{ }^{\circ} \mathrm{C}$ remained stable from 1988 to 1998 and increased rapidly from $14.9 \%$ in 1998 to $32 \%$ in 2019. In addition to summer, thermal environment issues are also evident in spring and fall because it is common for RLST to exceed $2{ }^{\circ} \mathrm{C}$ in these seasons.

The cooling effect of different types of blue-green space is clearly different. Among the types of blue-green space, water exhibits the best cooling effect in all seasons. The cooling effect of forest is notably better than that of cropland (rice paddy fields), apart from in summer. Over the study period, the temperature increases caused by the change in land use from water, cropland, and forest to built-up areas were $1.39,1.17$, and $1.1{ }^{\circ} \mathrm{C}$, respectively.

The transformation from non-blue-green spaces into water has the greatest average cooling effect. When built-up or bare land was converted to water, the average cooling effect was -0.91 and $-0.96{ }^{\circ} \mathrm{C}$, respectively. Among the types of blue-green space, the loss of water has the most severe heating effect of $0.61-2.51{ }^{\circ} \mathrm{C}$, followed by the loss of cropland $\left(0.38-2.21{ }^{\circ} \mathrm{C}\right)$ and forest $\left(0.15-2.29^{\circ} \mathrm{C}\right)$.

\section{Acknowledgments}

This research was supported by a 2017 Research Grant from Kangwon National University (Project Number: D1001064-01-01) and conducted with the support of the Korea Environment Industry \& Technology Institute (KEITI) through its Urban Ecological Health Promotion Technology Development Project, and funded by the Korea Ministry of Environment (MOE) (2019002760001).

\section{References}

1 R. T. Forman: Urban Ecology: Science of Cities (CUP, Cambridge, 2014) Chap. 1.

2 A. J. Arnfield: Int. J. Climatol. 23 (2003) 1. https://doi.org/10.1002/joc.859

3 J. A. Voogt and T. R. Oke: Remote Sens. Environ. 86 (2003) 370. https://doi.org/10.1016/S0034-4257(03)000798

4 S. Galea and D. Vlahov: Annu. Rev. Public Health. 26 (2005) 341. https://doi.org/10.1146/annurev. publhealth.26.021304.144708 
5 M. Abbas, B. Jason, and J. B. Tristan: J. Environ. Manage. 197 (2017) 522. https://doi.org/10.1016/j. jenvman.2017.03.095

6 P. Hou and S. Wu: Sci. Rep. 6 (2016) 23792. https://doi.org/10.1038/srep23792

7 D. E. Bowler, L. M. Buyung-Ali, T. M. Knight, and A. S. Pullin: BMC Public Health 10 (2010) 456. https://doi. org/10.1186/1471-2458-10-456

8 S. Völker and T. Kistemann: Health Place 35 (2015) 196. https://doi.org/10.1016/j.healthplace.2014.10.015

9 G. Laschewski and G. Jendritzky: Clim. Res. 21 (2002) 91. https://doi.org/10.3354/cr021091

10 J. De Blois, T. Kjellstrom, S. Agewall, J. A. Ezekowitz, P. W. Armstrong, and D. Atar: Cardiology 131 (2015) 209. https://doi.org/10.1159/000398787

11 X. Cheng and H. Su: Eur. J. Intern. Med. 21 (2010) 164. https://doi.org/10.1016/j.ejim.2010.03.001

12 G. Luan, P. Yin, T. Li, L. Wang, and M. Zhou: Sci. Rep. 7 (2017) 13531. https://doi.org/10.1038/s41598-017$13225-2$

13 T. Kosatsky: Eur. Surveill. 10 (2005) 3. https://doi.org/10.2807/esm.10.07.00552-en

14 P. Xiao, X. Wang, X. Feng, X. Zhang, and Y. Yang: IEEE. J. Sel. Top Appl. Earth Obs. Remote Sens. 7 (2014) 4095. https://doi.org/10.1109/JSTARS.2014.2302855

15 National Bureau of Statistics: http://www.stats.gov.cn/ (accessed 24 April 2020).

16 W. Shen, J. He, C. Huang, and M. Li: Remote Sens. 12 (2020) 2354. https://doi.org/10.3390/rs12152354

17 S. H. Kil and Y. J. Yun: J. Forest Environ. Sci. 34 (2018) 246. https://doi.org/10.7747/JFES.2018.34.3.246

18 A. Buyantuyev and J. Wu: Landscape Ecol. 25 (2010) 17. https://doi.org/10.1007/s10980-009-9402-4

19 H. Y. Du, W. B. Cai, Y. Q. Xu, Z. B. Wang, Y. Y. Wang, and Y. L. Cai: Urban For. Urban Green. 27 (2017) 24. https://doi.org/10.1016/j.ufug.2017.06.008

20 M. Gascon, M. Triguero-Mas, D. Martinez, P. Dadvand, J. Forns, A. Plasencia, and M. J. Nieuwenhuijsen: Int. J. Environ. Res. Public Health 12 (2015) 4354. https://doi.org/10.3390/ijerph120404354

21 Y. B. Cai, Y. H. Chen, and C. Tong: Urban For. Urban Green. 41 (2019) 333. https://doi.org/10.1016/j. ufug.2019.04.012

22 A. M. Rizwan, L. Y. Dennis, and L. Chunho: J. Environ. Sci. 20 (2008) 120. https://doi.org/10.1016/S10010742(08)60019-4

23 J. Peng, P. Xie, Y. Liu, and Y. Ma: Remote Sens. Environ. 173 (2016) 145. https://doi.org/10.1016/j. rse.2015.11.027

24 H. Meng, J. Li, and X. He: Energy Procedia 157 (2019) 746. https://doi.org/10.1016/j.egypro.2018.11.240

25 K. Fanhua, Y. Haiwei, and L. Jinyong: J. Nat. Resour. 28 (2013) 171. https://doi.org/10.11849/zrzyxb.2013.01.017

26 J. H. Kim, W. Li, G. Newman, S. H. Kil, and S. Y. Park: Environ. Plan B-Urban. 45 (2018) 26. https://doi. org/10.1177/0265813516663932

27 H. Li, Y. N. Zeng, and Q. H. Liu: Remote Sens. Land Resour. 4 (2008) 47. https://doi.org/10.6046/ gtzyyg.2008.04.12

28 W. Yang, N. H. Wong, and G. Zhang: Int. J. Biometeorol. 57 (2013) 895. https://doi.org/10.1007/s00484-0120616-9

29 Y. Ye, J. X. Qin, and S. S. Hu: J. Geo-inf. Sci. 19 (2017) 518. https://doi.org/10.3724/SP.J.1047.2017.00518

30 T. Jianguo and Z. Youfei: Meteorol. Sci. Technol. 2 (2013) 347. https://doi.org/10.19517/j.1671-6345.2013.02.026.

31 Hunan Statistical Yearbook 2019: http://222.240.193.190/19tjnj/indexeh.htm (accessed 6 May 2020).

32 China Meteorological Data Service Center: http://data.cma.cn/ (accessed 20 August 2020).

33 Q. Y. Yu, W. J. Ji, R. L. Pu, S. Landry, M. Acheampong, J. O’Neil-Dunne, Z. B. Ren, and S. H. Tanim: Int. J. Appl. Earth Obs. 92 (2020) 102161. https://doi.org/10.1016/j.jag.2020.102161

34 Z. H. Qin and M. H. Zhang: Acta Geol. Sin. 56 (2001) 456. https://doi.org/10.11821/xb200104009

35 Z. H. Qin, W.J. Li, M. H. Zhang, A. Karnieli, and P. Berliner: Remote Sens. Land Resour. 15 (2003) 37. https:// doi.org/10.6046/gtzyyg.2003.02.10

36 Y. H. Chen, Y. B. Cai, and C. Tong: Environ. Monit. Assess 191 (2019) 121. https://doi.org/10.1007/s10661-0197213-X

37 D. Sun, M. Chen, Y. Chen, and Y. Wuzhati: Acta Geogr. Sin. 71 (2016) 1025. https://doi.org/10.11821/ dlxb201606010

38 D. Lee, K. Oh, and J. Seo: Int. J. Environ. Sci. Develop. 7 (2016) 810. https://doi.org/10.18178/ijesd.2016.7.11.886

39 G. Y. Yang, Z. W. Yu, G. Jørgensen, and H. Vejre: Sust. Cities Soc. 53 (2020) 101932. https://doi.org/10.1016/j. scs.2019.101932

40 W. Thiery, E. L. Davin, D. M. Lawrence, A. L. Hirsch, M. Hauser, and S. I. Seneviratne: J. Geophys. Res.Atmos. 122 (2017) 1403. https://doi.org/10.1002/2016JD025740

41 T. Liu, L. Yu, K. Bu, F. Yan, and S. Zhang: Remote Sens. 10 (2018) 2009. https://doi.org/10.3390/rs10122009

42 Y. Lu, K. Harding, and L. Kueppers: J. Clim. 30 (2017) 3671. https://doi.org/10.1175/JCLI-D-15-0706.1 


\section{About the Authors}

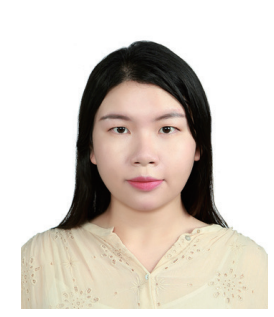

Xinyi Qiu is a Ph.D. candidate in the Department of Landscape Architecture, Kangwon National University, South Korea. Her research interests include urban thermal environments and ecological investigation using remote sensing of satellite images. (qiuxinyi@kangwon.ac.kr)

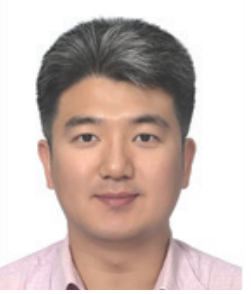

Sung-Ho Kil is an assistant professor at Kangwon National University. He graduated from Kangwon National University in 2003, majoring in landscape architecture. He earned his MLA and Ph.D. degrees from Seoul National University in 2007 and 2014, respectively. His research interests include ecological restoration, spatial ecology, and landscape ecology.

(sunghokil@kangwon.ac.kr)

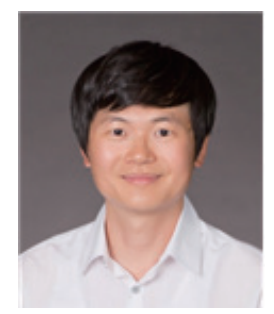

Chan Park is an associate professor at University of Seoul. He graduated from Seoul National University in 2007, majoring in landscape architecture. He earned his MLA and Ph.D. degrees from Seoul National University in 2009 and 2012, respectively. His research interests include climate change, social behavior, and spatial informatics. (chaneparkmomo7@uos.ac.kr) 